\title{
Talosins A and B: New Isoflavonol Glycosides with Potent Antifungal Activity from Kitasatospora kifunensis MJM341
}

\author{
I. Taxonomy, Fermentation, Isolation, and Biological Activities
}

Tae Mi Yoon, Jong Woo Kim, Jong Gwan Kim, Won Gon Kim, Joo Won Suh

Received: June 9, 2006 / Accepted: October 6, 2006

(C) Japan Antibiotics Research Association

\begin{abstract}
In our screening program for new antifungal agents from microbial secondary metabolites, we isolated two new isoflavonol glycosides, genistein 7- $\alpha$-L-6-deoxytalopyranoside (talosin A) and genistein $4^{\prime}, 7-\mathrm{di}-\alpha$-L-6deoxy-talopyranoside (talosin B), from the culture broth of Kitasatospora kifunensis MJM341. The talosins exhibited strong antifungal activity against Candida albicans, Aspergillus niger and Cryptococcus neoformans with minimal inhibitory concentrations (MIC) in the range of $3 \sim 15 \mu \mathrm{g} / \mathrm{ml}$ while genistein and genistein-7glucopyranoside did not show antifungal activity at $100 \mu \mathrm{g} / \mathrm{ml}$. These talosins are the first isoflavonol glycosides with a 6-deoxy-talose sugar component and they may be useful as antifungal agents with low toxicity because of no visible cytotoxicity against the human hepatic HepG2 cell.
\end{abstract}

Keywords Kitasatospora kifunensis, antifungal agent, isoflavonol glycoside, genistein, 6-deoxy-talose, talosin A, talosin B

\section{Introduction}

Although the number of potent bacterial pathogens has decreased markedly, opportunistic infections with Candida and Aspergillus have increased gradually. In addition, fungal diseases are increasing in immunocompromised hosts [1]. Such patients have a defect in their self-defense system as a result of AIDS or medication with immunosuppressive drugs, such as anticancer agents. Since the currently employed therapeutics have toxic side effects, the development of novel compounds, together with a search for new molecular targets, is greatly needed $[2,3]$. Therefore, we screened microbial natural products from approximately 800 actinomycete strains isolated from soil in South Korea. In our screening program for new and low cytotoxic antifungal agents from microbial secondary metabolites, we isolated two new isoflavonol glycosides with potent antifungal activity, talosins $\mathrm{A}$ and $\mathrm{B}$, from the culture broth of Kitasatospora kifunensis MJM341. Talosins A and B were determined to be genistein 7- $\alpha$-L-6deoxy-talopyranoside and genistein $4^{\prime}, 7$-di- $\alpha$-L-6-deoxytalopyranoside, respectively (Fig. 1). The producing strain MJM341 was isolated from a soil sample collected from Gyeonggi province, Korea, and identified as Kitasatospora kifunensis based on a 16S rDNA sequence. Kitasatospora kifunensis is known to produce kifunensin as an immunomodulator [4], but there is no report of antifungal production from this species.

In this study we will demonstrate that talosin A and talosin B show strong antifungal activity, but no
J. W. Suh (Corresponding author), T. M. Yoon: Institute of Bioscience and Biotechnology, Department of Biological Science, Myongji University, Yongin, Gyeonggi-Do, 449-728, Korea, E-mail: jwsuh@mju.ac.kr

J. W. Suh, T. M. Yoon, J. G. Kim: Extract Collection of Useful Microorganism (ECUM), Beakmagwan 2229, Myongji University, Yongin, Gyeonggi-Do, 449-728, Korea
J. W. Kim: B\&C Biopharm. IAE Bldg, 633-2, Goan-ri, Beagammyeon, Yongin, Gyeonggi-Do, 449-863, Korea

W. G. Kim: Korea Research Institute of Bioscience and Biotechnology, P.O. Box 115, Yuseong, Daejeon, 305-600, Korea 


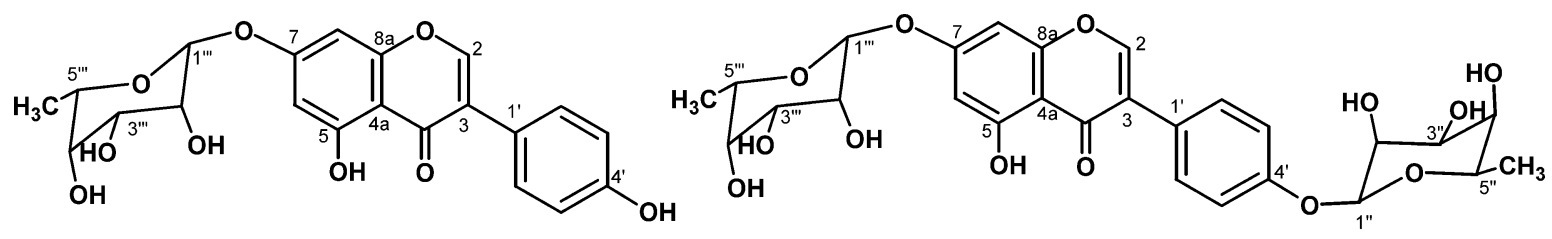

Fig. 1 Chemical structures of talosins A (1) and B (2).

cytotoxicity against the human hepatic HepG2 cell. In this paper, we describe the taxonomy, fermentation, isolation, and biological properties of the novel isoflavonol glycosides, and the structure determination will be described in a following paper [5].

\section{Materials and Methods}

\section{Screening and Taxonomy}

Strain MJM341 was isolated from a suspension of a soil sample inoculated onto a starch-casein $\mathrm{KNO}_{3}$ agar (starch $1 \%, \mathrm{KNO}_{3} 0.2 \%, \mathrm{~K}_{2} \mathrm{HPO}_{4} 0.2 \%, \mathrm{NaCl} 0.2 \%$, casein $0.03 \%$, $\mathrm{MgSO}_{4} \cdot 7 \mathrm{H}_{2} \mathrm{O} \quad 0.005 \%, \mathrm{CaCO}_{3} 0.002 \%, \mathrm{FeSO}_{4} \cdot 7 \mathrm{H}_{2} \mathrm{O}$ $0.001 \%$, agar $1.8 \%$ ) plates and incubated at $28^{\circ} \mathrm{C}$ for 2 weeks [6]. The soil samples were collected from the Gyeonggi province in South Korea. The isolates were individually maintained on starch - casein $\mathrm{KNO}_{3}$ agar at $4^{\circ} \mathrm{C}$ and stored as a mixture of hyphae and spores in $20 \%$ glycerol at $-80^{\circ} \mathrm{C}$. Each isolated strain was cultured in a GSS liquid medium (soluble starch $1 \%$, glucose $2 \%$, soybean meal $2.5 \%$, beef extract $0.1 \%$, yeast extract $0.4 \%$, $\mathrm{NaCl} 0.2 \%, \mathrm{~K}_{2} \mathrm{HPO}_{4} 0.025 \%, \mathrm{CaCO}_{3} 0.2 \%, \mathrm{pH} 7.2$ ) at $28^{\circ} \mathrm{C}$ for 7 days. After clarification of the culture broths, the supernatant and methanol extract of mycelia were tested for antifungal activity and cytotoxicity.

The antifungal strains with the biggest inhibition zones and no cytotoxicity were identified by an analysis of the 16S rDNA sequence using primers fD1 and rP2 [7]. The amplified 16S rDNA gene fragment was ligated into a pGEM T-Easy vector and then transformed into $E$. coli DH5 $\alpha$. The plasmids, purified with a Wizard plasmid prep kit (Promega, USA), were sequenced. The sequence was aligned using CLUSTAL W software [8] and a phylogenic tree was constructed using the neighbor-joining method [9]. The morphological characteristics of the spores and mycelia grown on ISP4 for 14 days at $28^{\circ} \mathrm{C}$ were observed using a scanning electron microscope (S-3500N, Hitachi, Japan). The cultural and physiological characteristics were determined using the same methods of Shirling and
Gottlieb [10]. Diaminopimelic acid (DAP) analysis was performed according to the procedure of Lechevalier [11]. The color of colony's surface was specified according to the symbols described in the Methuen Handbook of Colour [12].

\section{Biological Assay}

Antifungal activity was primarily evaluated by a paper disc assay against Candida albicans and the activity was determined by the diameter of the clear zone. The minimal inhibitory concentration (MIC) values against the pathogenic fungi were determined using the broth dilution method.

Cytotoxicity was tested with the human hepatic HepG2 cell which was maintained in RPMI 1640 medium (Life Technology, USA) containing $10 \%$ FBS and $20 \mu \mathrm{g} / \mathrm{ml}$ kanamycin. The $\mathrm{CC}_{50}$ values ( $50 \%$ cytotoxic concentration) against the HepG2 cell line was analyzed using an MTT assay after incubation at $37^{\circ} \mathrm{C}$ for 72 hours with an inoculum size of $10^{4}$ cells $/ \mathrm{ml}$. The results were measured at $540 \mathrm{~nm}$ with a microplate reader (Bio-Rad Model 3550, USA).

\section{Fermentation}

Kitasatospora kifunensis MJM341 was maintained on starch casein $\mathrm{KNO}_{3}$ agar medium. A slant culture was inoculated into a $500 \mathrm{ml}$ baffled flask containing $70 \mathrm{ml}$ of Bennett's medium. The cultures were incubated on a rotary shaker at $200 \mathrm{rpm}$ at $28^{\circ} \mathrm{C}$ for 24 hours. Five milliliters of the seed culture were inoculated into a 2-liter baffled flask containing $500 \mathrm{ml}$ of the GSS medium to produce the antifungal compounds. The fermentation was carried out for 6 days under similar conditions.

\section{Results}

\section{Taxonomy of the Producing Strain}

The MJM341 strain was selected from approximately 800 actinomycetes collected from the Gyeonggi province in 


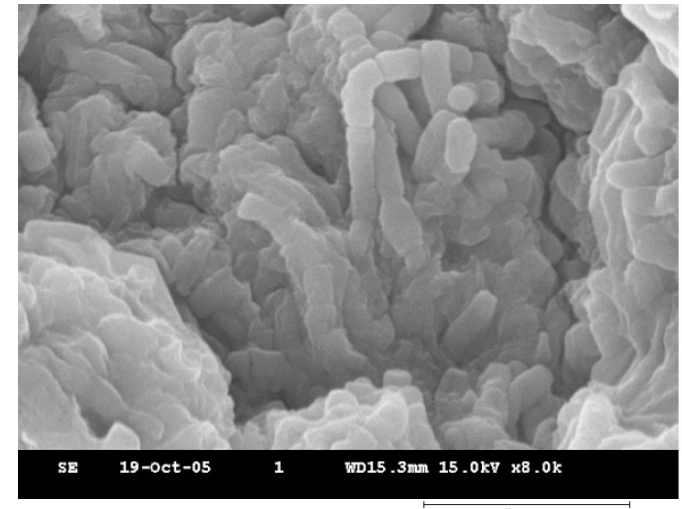

$5 \mu \mathrm{m}$

(A) Kitasatospora kifunensis MJM341

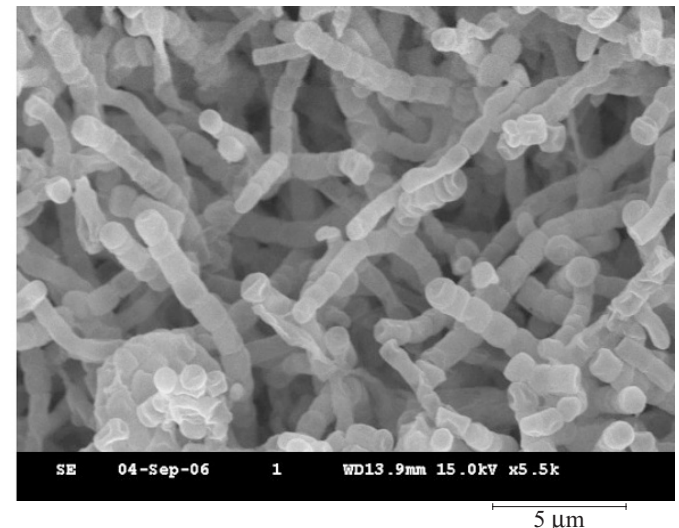

(B) Kitasatospora kifunensis NBRC $15206^{\top}$

Fig. 2 Scanning electron micrograph of spore chains of Kitasatospora kifunensis MJM341 and Kitasatospora kifunensis NBRC $15206^{\top}$.

Table 1 Cultural characteristics of strain MJM341

\begin{tabular}{|c|c|c|c|c|}
\hline Medium & Growth & Aerial mycelium & Reverse side color & Soluble pigment \\
\hline Yeast extract - malt extract agar & Good & Yellowish white [3A2] & Yellowish brown [5D4] & None \\
\hline Oatmeal agar & Good & Gray [4C1] & Brown [6F6] & None \\
\hline Inorganic salts - starch agar & Good & Gray $[4 \mathrm{C} 1]$ & Pale yellow [3A3] & None \\
\hline Glycerol asparagine agar & Good & Yellowish white [3A2] & Pale yellow [3A3] & None \\
\hline Peptone - yeast extract - iron agar & Good & Pale yellow [3A3] & Pale yellow [3A3] & None \\
\hline Tyrosine agar & Good & Yellowish white [3A2] & Grayish brown [6E3] & None \\
\hline
\end{tabular}

South Korea. Most of the culture broths with strong antifungal activity showed powerful cytotoxicity, but supernatant of strain MJM341 had no cytotoxic activity. This strain was identified as a Kitasatospora kifunensis species by a $16 \mathrm{~S}$ rDNA sequence analysis with $99 \%$ identity. Consequently, we designated our strain as Kitasatospora kifunensis MJM341.

For the morphological characteristics of the MJM341 strain, the aerial mycelium of the cultured strain was extensively branched and consisted of straight chains with smooth-surfaced spores. The size of each rod-shaped spore was approximately $0.8 \times 1.6 \mu \mathrm{m}$ (Fig. 2). The culture characteristics are shown in Table 1. The color of the aerial mycelium was yellowish-white to gray on an ISP media No. $2 \sim 7$ and a soluble pigment was not observed. The chemical and physiological properties of strain MJM341 and Kitasatospora kifunensis NBRC 15206 are summarized in Table 2. Strain MJM341 was an unusal strain because it had a much higher ratio of LL-DAP to meso-DAP and galactose in whole cell hydrolysates, while Kitasatospora kifunensis NBRC $15206^{\mathrm{T}}$ contained LL-DAP, meso-DAP and galactose. Strain MJM341 used most of carbohydrates and nitrogens with the exception of sodium-acetate. Kitasatospora kifunensis NBRC $15206^{\mathrm{T}}$ utilized the major part of nitrogens, but it poorly used carbon sources.

\section{Fermentation}

Figure 3 shows the time course of talosin A and talosin B productions by the MJM341 strain in a 2-liter baffled flask, along with the cell growth. Maximum growth was observed on day 4 after the inoculation. Production of talosin B began after 24 hours and maximum production was reached on day 7, with a yield of $3.2 \mathrm{mg} /$ liter. Talosin A was produced earlier than talosin $\mathrm{B}$, but its production decreased transiently on day 5 .

\section{Purification}

The entire culture broth (40 liters) was centrifuged (6,500 rpm, 15 minutes) to separate the mycelium and the supernatant. The supernatant was extracted with butanol $(1: 1, \mathrm{v} / \mathrm{v})$ and the organic layer was evaporated to give an oily material $(16.2 \mathrm{~g})$. The oily material was then dissolved 
Table 2 Chemical and physiological properties of strain MJM341 and Kitasatospora kifunensis NBRC $15206^{\top}$

\begin{tabular}{|c|c|c|}
\hline Characteristics & $\begin{array}{c}\text { K. kifunensis } \\
\text { MJM341 }\end{array}$ & 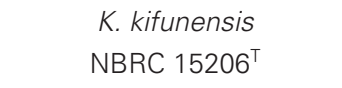 \\
\hline Wall chemotype & LL-DAP, meso-DAP, glycine & LL-DAP, meso-DAP, glycine \\
\hline Whole-cell sugar pattern & galactose & galactose \\
\hline Temperature range for growth (ISP2 No. 2) & $15 \sim 37^{\circ} \mathrm{C}$ & $15 \sim 37^{\circ} \mathrm{C}$ \\
\hline Optimum temperature for growth (ISP No. 2) & $20 \sim 33^{\circ} \mathrm{C}$ & $20 \sim 33^{\circ} \mathrm{C}$ \\
\hline \multicolumn{3}{|l|}{ Melanin pigmenet production } \\
\hline Peptone-yeast extract-iron agar (ISP No. 6) & - & - \\
\hline Tyrosine agar (ISP No. 7) & - & + \\
\hline \multicolumn{3}{|l|}{ Degradation activity } \\
\hline Casein & - & - \\
\hline Starch & + & - \\
\hline Gelatin & + & + \\
\hline \multicolumn{3}{|l|}{ Enzyme activity } \\
\hline Nitrate reduction & + & + \\
\hline $\mathrm{H}_{2} \mathrm{~S}$ production & - & - \\
\hline Lecithinase & + & + \\
\hline \multicolumn{3}{|l|}{ Resistance to antibiotics ( $\mu \mathrm{g} / \mathrm{ml})$} \\
\hline Neomycin (50) & - & - \\
\hline Oleandomycin (100) & - & - \\
\hline Streptomycin (100) & - & - \\
\hline Tobramycin (50) & - & - \\
\hline \multicolumn{3}{|c|}{ Growth in the presence of chemical inhibitors (\% w/v) } \\
\hline Crystal violet (0.0001) & + & + \\
\hline Sodium azide (0.02) & + & - \\
\hline Sodium chloride (4) & - & - \\
\hline \multicolumn{3}{|l|}{ Antimicrobial activity } \\
\hline Aspergillus niger & + & + \\
\hline Bacillus subtilis & - & + \\
\hline Candida albicans & + & + \\
\hline Escherichia coli & - & - \\
\hline \multicolumn{3}{|l|}{ Use of carbon sources $(1.0 \% \mathrm{w} / \mathrm{v})$} \\
\hline D-Glucose & + & + \\
\hline D-Xylose & + & + \\
\hline D-Fructose & + & \pm \\
\hline D-Galactose & + & \pm \\
\hline D-Arabinose & + & \pm \\
\hline D-Mannose & + & - \\
\hline L-Rhamnose & + & \pm \\
\hline Na-acetate & - & - \\
\hline Sucrose & + & \pm \\
\hline \multicolumn{3}{|l|}{ Use of nitrogen sources $(0.1 \% \mathrm{w} / \mathrm{v})$} \\
\hline L-Asparagine & + & + \\
\hline L-Methionine & + & + \\
\hline L-Histidine & + & + \\
\hline L-Valine & + & + \\
\hline L-Threonine & + & + \\
\hline L-Phenylalanine & + & + \\
\hline
\end{tabular}

+; positive, \pm ; slightly positive, -; negative 


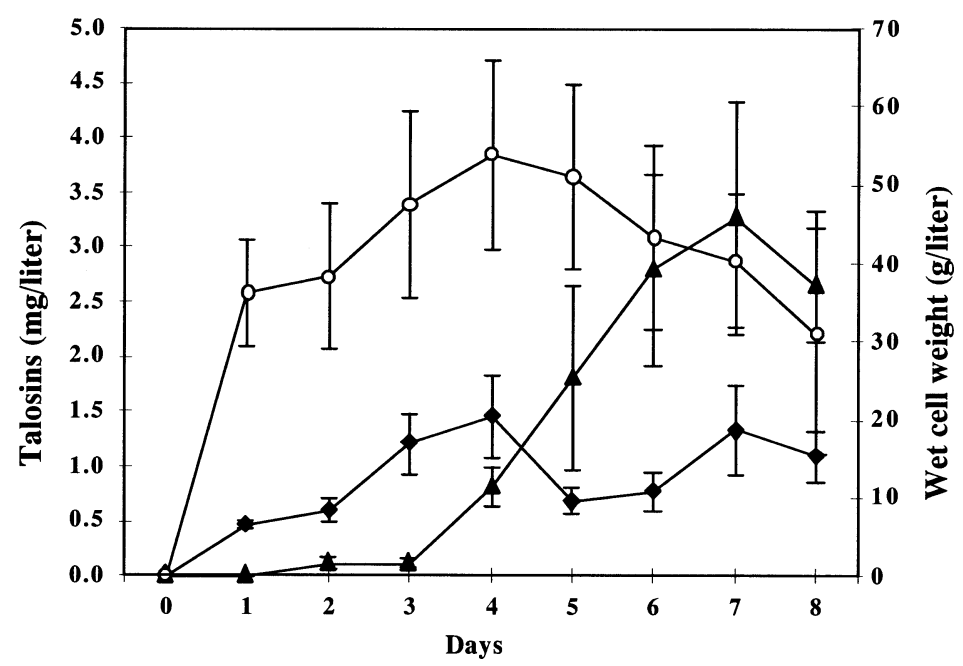

Fig. 3 Fermentation profiles for the production of talosins $A$ and $B$.

$\bullet$ : Talosin A; $\mathbf{\Delta}$ : talosin B; O: wet cell weight.

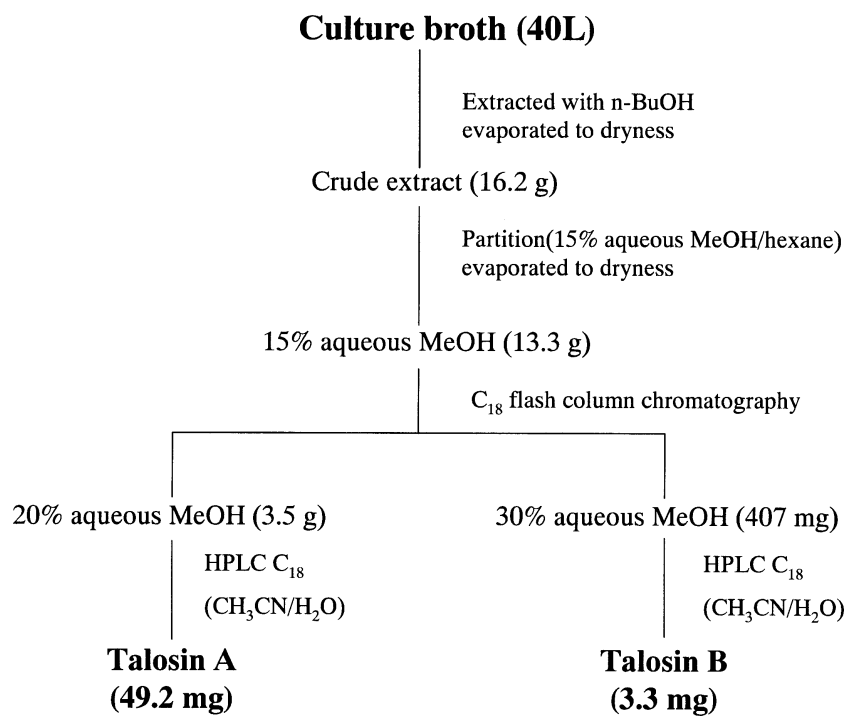

Fig. 4 Purification of talosins A and B from Kitasatospora kifunensis MJM341.

in $15 \%$ aqueous methanol and defatted by partitioning with $n$-hexane to give a solid extract. The biologically active $15 \%$ aqueous methanol layer $(13.3 \mathrm{~g})$ was separated using $\mathrm{C}_{18}$ reversed-phase vacuum flash column chromatography with sequential mixtures of $\mathrm{MeOH}$ and water as eluents (elution order: 50, 30, 20, 10\% aqueous $\mathrm{MeOH}$ and $100 \%$ $\mathrm{MeOH})$. The fraction (3.5 g) eluted with $20 \%$ aqueous $\mathrm{MeOH}$ that showed mild antifungal activity was separated by $\mathrm{C}_{18}$ reversed-phase HPLC (semi-preparative Symmetry RP-18 column, Waters, USA, solvent: $72 \%$ aqueous acetonitrile) to yield the active compound talosin A $(49.2 \mathrm{mg})$. The fraction $(407 \mathrm{mg})$ eluted with $30 \%$ aqueous $\mathrm{MeOH}$ that showed the highest antifungal activity was separated under similar conditions with $72 \%$ aqueous acetonitrile to yield the active compound talosin B (3.3 mg) (Fig. 4).

\section{Antifungal Activity}

The antifungal activities of talosin $\mathrm{A}$ and talosin $\mathrm{B}$ were determined as MIC against Candida albicans, Cryptococcus neoformans, and Aspergillus niger, which cause systemic mycosis. Talosin B was more potent than talosin A; the MIC values were $3 \sim 15 \mu \mathrm{g} / \mathrm{ml}$, so the talosins are slightly weaker than amphotericin $\mathrm{B}$ in regards to antifungal activity [13]. Both of the talosins did not inhibit Bacillus subtilis and Serratia marcescens (data not shown) 
Table 3 Antifungal activity (MIC) of talosins A and B

\begin{tabular}{lccrrr}
\hline \multicolumn{1}{c}{ Test strains } & $\begin{array}{c}\text { Genistein } \\
(\mu \mathrm{g} / \mathrm{ml})\end{array}$ & $\begin{array}{c}\text { Genistin } \\
(\mu \mathrm{g} / \mathrm{ml})\end{array}$ & $\begin{array}{c}\text { Talosin A } \\
(\mu \mathrm{g} / \mathrm{ml})\end{array}$ & $\begin{array}{c}\text { Talosin B } \\
(\mu \mathrm{g} / \mathrm{ml})\end{array}$ & $\begin{array}{c}\text { Amphotericin B } \\
(\mu \mathrm{g} / \mathrm{ml})\end{array}$ \\
\hline Candida albicans B 02630 & $>100$ & $>100$ & 15 & 7 & $0.1-1$ \\
Cryptococcus neoformans B 42419 & $>100$ & $>100$ & 7 & 3 & $0.1-1$ \\
Aspergillus niger ATCC 6275 & $>100$ & $>100$ & 6 & 3 & $1-2$ \\
Trichophyton mentagrophytes ATCC 9129 & $>100$ & $>100$ & $>100$ & $->100$ \\
\hline
\end{tabular}

and the dermatomycosis pathogen Trichophyton mentagrophytes. Genistein without sugar and genistin (genistein 7-glucopyranoside) did not show antifungal activity at $100 \mu \mathrm{g} / \mathrm{ml}$ (Table 3 ).

\section{Cytotoxic Activity}

The cytotoxic acticities of talosins $\mathrm{A}$ and $\mathrm{B}$ were determined against the human hepatic HepG2 cell. The $\mathrm{CC}_{50}$ values were $100 \mu \mathrm{g} / \mathrm{ml}$ and the $\mathrm{MCD}$ (minimal cytotoxic density) was $50 \mu \mathrm{g} / \mathrm{ml}$ (Table 4). Thus, the two talosins did not have significant cytotoxicity.

\section{Discussion}

There is an increasing need for safe and effective antifungal agents because systemic mycosis has been a major cause of deaths in immunosuppressed patients in recent years [1]. New approaches for the treatment of invasive fungal infections are necessary because the incidence of infections has risen steadily since the 1970s [14]. Azole and amphotericin B are currently the most widely used antifungal agents, but these show serious cytotoxicity and side effects [15].

In the course of screening for new and safe antifungal agents, we discovered two new compounds; talosin $\mathrm{A}$ and talosin B. Based on physicochemical data, GC analysis of the sugar [16] and 2D-NMR spectra, these new compounds have novel structures. Talosins A and B are isoflavonol glycosides that consisted of genistein and 6-deoxy-talose. Talosin A is substituted by only one 6-deoxy-talose at the C-7 hydroxyl group and talosin B is substituted by two 6-deoxy-taloses at the C-4' and C-7 hydroxyl groups of the aglycone. Thus, the structures of talosins $\mathrm{A}$ and $\mathrm{B}$ have been determined as genistein 7- $\alpha$-L-6-deoxy-talopyranoside and genistein 4',7-di- $\alpha$-L-6-deoxy-talopyranoside, respectively (Fig. 1).

The stereochemistry of 6-deoxy-talose is different with regards to rhamnose at the $\mathrm{C}-4$ position. It has been reported that Aeromonas hydrophila, Burkholderia
Table 4 Cytotoxic activity of talosins A and B

\begin{tabular}{lccc}
\hline & $\begin{array}{c}\text { Amphotericin B } \\
(\mu \mathrm{g} / \mathrm{ml})\end{array}$ & $\begin{array}{c}\text { Talosin A } \\
(\mu \mathrm{g} / \mathrm{ml})\end{array}$ & $\begin{array}{c}(\mu \mathrm{g} / \mathrm{ml}) \\
\end{array}$ \\
\hline $\begin{array}{l}\text { MCD } \\
\text { (minimal cytotoxic density) }\end{array}$ & 1.20 & 50 & 50 \\
$\mathrm{CC}_{50}$ & & & \\
$(50 \%$ cytotoxic concentration) & 1.56 & $>100$ & $>100$ \\
\hline
\end{tabular}

caribensis and Escherichia coli contain 6-deoxy-talose as a constituent of O polysaccharide [17 19], and Actinomyces bovis has 6-deoxy-talose as a cell wall component [20]. However, talosins $\mathrm{A}$ and $\mathrm{B}$ are the first bioactive isoflavonols with 6-deoxy-talose as a sugar component.

Umezawa's group isolated genistein 4',7-dirhamnopyranoside and genistein 7-rhamnopyranoside, which were stereochemically different from talosins A and B, from Streptomyces xanthophaeus in 1979 [21]. They reported that these compounds showed no antifungal activities at $100 \mu \mathrm{g} / \mathrm{ml}$, in contrast to our compounds [22]. Furthermore, genistein itself and genistin (genistein 7-glucopyranoside) did not inhibit yeasts and fungi at $100 \mu \mathrm{g} / \mathrm{ml}$. Therefore, we propose that 6-deoxy-talose plays an important role in the antifungal effects.

Kitasatospora kifunensis MJM341 did not produce talosin A and talosin B in GSS medium without soybean meal, and we could not isolate a biosynthetic gene cluster of genistein from the Kitasatospora kifunensis MJM341 genome. Accordingly, it is suggested that strain MJM341 combined its own 6-deoxy-talose to the genistein of the soybean meal by glycosyltransferase. We are now attempting to obtain the gene cluster for the nucleotide diphosphate (NDP)-6-deoxy-talose biosynthesis for industrial applications [23].

Talosin B inhibits Cryptococcus neoformans approximately 3 30 more weakly than amphotericin B [13], but does not exhibit significant cytotoxicity (Table 4). Therefore, the side effects of the talosins may be remarkably low and they may have potential for therapeutic 
applications. Pharmacokinetic tests may be necessary for the development of antifungal therapy products after obtaining large amounts of the talosins.

Acknowledgment This study was supported by a grant (20050301-034-425-045-01-00) from the BioGreen 21 Program of the Rural Development Administration, Republic of Korea. This work was also partially supported by the Korean National Research Resource Center (KNRRC) Project to ECUM (Extract Collection of Useful Microorganism) from the Korean Ministry of Science and Technology. The authors acknowledge this support.

\section{References}

1. Sternberg S. The emerging fungal treatment. Science 226: 1632-1634 (1994)

2. Georgopapadakou NH, Walsh TJ. Antifungal agents: Chemotherapeutic targets and immunologic strategies. Antimicrob Agents Chemother 40: 279-291 (1996)

3. Vincente MF, Basilio A, Pelaez F. Microbial natural products as a source of antifungals. Clin Microbiol Infect 9: 15-32 (2003)

4. Iwami M, Nakayama O, Terano H, Kohsaka M, Aoki H, Imanaki H. A new immunomodulator, FR-900494: Taxonomy, fermentation, isolation, and physico-chemical and biological characteristics. J Antibiot 40: 612-622 (1987)

5. Kim WG, Yoon TM, Kwon HJ, Suh JW. Talosins A and B, new isoflavonol glycosides with potent antifungal activity from Kitasatospora kifunensis MJM341. II. Physicochemical properties and structure determination. J Antibiot 59: 640-645 (2006)

6. Kim CJ, Lee KH, Kwon OS, Shimazu A, Yoo ID. Selective isolation of actinomycetes by physical pretreatment of soil sample. Kor J Appl Microbiol Biotechnol 22: 222-225 (1994)

7. Chun J, Goodfellow M. A phylogenetic analysis of the genus Nocardia with 16S rRNA gene sequences. Int J Syst Bacteriol 45: 240-245 (1995)

8. Thompson JD, Higgins DG, Gibson TJ. CLUSTAL W: improving the sensitivity of progressive multiple sequence alignment through sequence weighting, position-specific gap penalties and weight matrix choice. Nucleic Acids Res 22: 4673-4680 (1994)

9. Saitou N, Nei M. The neighbor-joining method: a new method for reconstructing phylogenetic trees. Mol Biol Evol 4: 406-425 (1987)

10. Shring EB, Gottlieb D. Methods for characterization of
Streptomyces species. Int J Syst Bacteriol 16: 313-340 (1966)

11. Becker B, Lechevalier MP, Gordon RE, Lechevalier HA. Rapid differentiation between Norcardia and Streptomyces by paper chromatography of whole-cell hydrolysates. Appl Microbiol 12: 421-423 (1964)

12. Kornerup A, Wanscher JH. Methuen Handbook of Colour. 3rd ed. Eyre Methuen Ltd. (1981)

13. Bolard J. How do the polyene macrolide antibiotics affect the cellular membrane properties? Brochim Biophys Acta 864: 257-304 (1986)

14. Ghannoum MA, Rice LB. Antifungal agents: mode of action, mechanism of resistance, and correlation of these mechanisms with bacterial resistance. Clin Microbiol Rev 12: 501-517 (1999)

15. Sheehan DJ, Hitchcock CA, Sibley CM. Current and emerging azole antifungal agents. Clin Microbiol Rev 12: 40-79 (1999)

16. Doco T, O'Neil MA, Pellerin P. Determination of the neutral and acidic glycosyl-residue compositions of plant polysaccharides by GC-EI-MS analysis of the trimethylsilyl methyl glycoside derivatives. Carbohydr Res 46: 249-259 (2001)

17. Knirel YA, Shashkov AS, Senchenkova SN, Merino S, Tomas JM. Structure of the $O$-polysaccharide of Aeromonas hydrophila O:34; a case of random $O$-acetylation of 6deoxy-L-talose. Carbohydr Res 337: 1381-1386 (2002)

18. Vanhaverbeke C, Heyraund A, Achouak W, Heulin T. Structural analysis of the exopolysaccharide from Burkholderia caribensis strain MWAP71. Carbohydr Res 334: 127-133 (2001)

19. Torgov VI, Shashkov AS, Kochanowski H, Jann B, Jann K. NMR analysis of the structure of the O88 polysaccharide (O88 antigen) of Escherichia coli $\mathrm{O} 88: \mathrm{k}^{-}: \mathrm{H} 25$. Carbohydr Res 283: 223-227 (1996)

20. Maclennan AP. Composition of the cell wall of Actinomyces Bovis: the isolation of 6-deoxy-L-talose. Biochim Biophys Acta 48: 600-601 (1961)

21. Hazato T, Naganawa H, Kumagai M, Aoyagi T, Umezawa H. $\beta$-Galactosidase-inhibiting new isoflavonoids produced by actinomycetes. J Antibiot 32: 217-222 (1979)

22. Aoyagi T, Hazato T, Kumagai M, Hamada M, Takeuchi T, Umezawa $H$. Isoflavone rhamnosides, inhibitors of $\beta$ galactosidase produced by actinomycetes. J Antibiot 28: 1006-1008 (1975)

23. Decker H, Gaisser S, Pelzer S, Schneider P, Westrich L, Wohlleben W, Bechthold A. A general approach for cloning and characterizing dNDP-glucose dehydratase genes from actinomycetes. FEMS Microbiol Lett 141: 195-201 (1996) 